\title{
COMPARISON OF ROBUST ESTIMATORS FOR LEVELING NETWORKS IN MONTE CARLO SIMULATIONS
}

\author{
Maria Pokarowska \\ Faculty of Geodesy and Cartography, \\ Warsaw University of Technology \\ Warsaw, Poland
}

\begin{abstract}
We compared the method of least squares (LS), Pope's iterative data snooping (IDS) and Huber's M-estimator (HU) in realistic leveling networks, for which the heights or the vertical displacements of points are known. The study was conducted using the Monte Carlo simulation, in which one repeatedly generates sets of observations related to the measurement data, then calculates values of the estimators and, finally, assesses it with respect to the real coordinates. To simulate outliers we used popular mixture models with two or more normal distributions. It is shown that for small, strong networks robust methods IDS and HU are more accurate than LS, but for large, weak networks occurring in practice there is no significant difference between the considered methods in the accuracy of the solution.
\end{abstract}

Keywords: leveling network, robust estimation, outliers, gross errors, internal reliability index

\section{Introduction}

Sometimes measurements in leveling networks are subject to gross contaminations that significantly affect the estimators of heights or vertical displacements of points determined by the least squares method (LS). In order to reduce the impact of possible gross errors, the robust estimators are employed. The essence of these methods is to repeatedly use LS with a simultaneous updating weights of observations such that outliers have less impact on the resulting solution. In these iterations as outliers we consider observations, for which the calculated normalized residuals exceed a given critical value.

In literature, there are currently many different methods of robust estimation. For short introduction we refer to Knight and Wang (2009) and for broad overview to Huber and Ronchetti (2009). In particular we have, popular in geodesy, methods 
which combine LS with statistical testing for normalized residuals such as the Baarda's or the Pope's iterative data snooping (IDS). Moreover, there are Mestimators minimizing error functions which increase slower than a quadratic function used by LS. One of the most well-known methods in this group is Huber's estimator $(\mathrm{HU})$.

In this work we compare accuracy of LS, IDS and HU methods in systematic, extensive Monte-Carlo simulations using four realistic leveling networks and popular models of gross errors that are mixtures of two or more normal distributions.

\section{Linear model for geodetic networks}

To find heights or displacements of points we will use the linear model:

$$
\widetilde{\mathbf{A}} \mathbf{x}+\widetilde{\boldsymbol{\varepsilon}}=\widetilde{\mathbf{y}}
$$

where $\widetilde{\mathbf{A}}$ is a $n \times p$ design matrix, $\mathbf{x}$ is a vector of $p$ parameters, $\widetilde{\boldsymbol{\varepsilon}}$ is a vector of $n$ random errors in measurements and $\tilde{\mathbf{y}}$ is a vector of $n$ observations. We assume that $E(\widetilde{\boldsymbol{\varepsilon}})=0, \quad \operatorname{var}(\widetilde{\boldsymbol{\varepsilon}})=\sigma^{2} \mathbf{P}^{-1}$, where $\mathbf{P}$ is a diagonal matrix of weights. The observations are height differences between benchmarks, which constitute the end points of leveling sections. Usually they are assigned weights inversely proportional to the number of stations: $p_{i}=n_{i}^{-1}$, where $n_{i}$ - number of stations for $i$-th leveling section.

After multiplying both sides of the equation (1) by $\mathbf{P}^{1 / 2}$, we obtain the homoscedastic linear model

$$
\mathbf{A x}+\boldsymbol{\varepsilon}=\mathbf{y}
$$

where $\quad \mathbf{A}=\mathbf{P}^{1 / 2} \widetilde{\mathbf{A}}, \boldsymbol{\varepsilon}=\mathbf{P}^{1 / 2} \widetilde{\boldsymbol{\varepsilon}}, \mathbf{y}=\mathbf{P}^{1 / 2} \widetilde{\mathbf{y}}, \quad E(\boldsymbol{\varepsilon})=0 \quad$ and $\quad \operatorname{var}(\boldsymbol{\varepsilon})=\sigma^{2} \mathbf{I}_{n}$. Moreover $\sigma=\sigma_{0} \sigma_{f}$, where $\sigma_{0}$ is a priori average error of observation and $\sigma_{f}$ is a standard deviation of the gross error distribution with density $f$. The internal reliability index of the $i$-th observation is defined as $\sqrt{1-\mathbf{H}_{i i}}$, where $\mathbf{H}_{i i}$ denotes the $i$-th diagonal element of the matrix $\mathbf{H}=\mathbf{A}\left(\mathbf{A}^{T} \mathbf{A}\right)^{-1} \mathbf{A}^{T}$.

\section{Estimators of the vector $\mathbf{x}$}

In our experiments we compare accuracy of the three following estimators of the vector $\mathbf{x}$ :

1. $\hat{\mathbf{x}}_{L S}$ - the classical least squares estimator (LS),

2. $\hat{\mathbf{x}}_{I D S}$ - Pope's version of the iterative data snooping estimator (IDS) with unknown $\sigma_{0}$, that is LS in which the largest standardized residual is repeatedly removed from the dataset if it is greater than a critical value equals 2.5 as in Kwaśniak (2011) , and

3. $\hat{\mathbf{x}}_{H U}$ - the Huber estimator (HU) that is the well-known M-estimator, which minimize a spline of quadratic and linear functions in a knot equals 1.345 with a scale factor estimated by the Median Absolute Deviation. For details see 
Knight and Wang (2009). These values are also default in the free statistical software R, which we used in simulations (R Core Team 2013).

As an error of estimation we compute in the $k$-th simulation, similarly as in Kwaśniak (2011), average $L_{2}$ distance:

$$
\operatorname{errMET}_{k}:=\left\|\hat{\mathbf{x}}_{M E T}^{(k)}-\mathbf{x}\right\| / \sqrt{p}
$$

where $M E T \in\{L S, I D S, H U\}$

The result of the simulation for the method MET is given by the vector $\operatorname{errMET}=\left[\operatorname{errMET}{ }_{1}, \ldots, \operatorname{errMET}_{K}\right]^{T}$.

\section{Gross errors distributions}

Let $\phi(x \mid \mu, \sigma)$ denote a density of normal distribution with mean $\mu$ and standard deviation $\sigma$. We consider three classical models of contamination of the typical measurement error defined by $\phi(x \mid 0,1)$. All these models are given by mixtures of normal densities. In the first model we assume that the measurement error comes from $t$ Student distribution with density $\tau(x \mid v)$, where $v>2$ denotes degrees of freedom. Such model has been recently analysed in Koch and Kargoll (2013). Moreover, we consider the following models:

$$
\begin{gathered}
f_{1}\left(x \mid \alpha, \sigma_{1}\right)=(1-\alpha) \phi(x \mid 0,1)+\alpha \phi\left(x \mid 0, \sigma_{1}\right), \\
f_{2}\left(x \mid \alpha, \mu_{1}, \sigma_{1}\right)=(1-\alpha) \phi(x \mid 0,1)+\frac{\alpha}{2} \phi\left(x \mid-\mu_{1}, \sigma_{1}\right)+\frac{\alpha}{2} \phi\left(x \mid \mu_{1}, \sigma_{1}\right),
\end{gathered}
$$

where $0 \leq \alpha \leq 1, \mu_{1} \geq 0, \sigma_{1} \geq 1$. The model $f_{1}$ is popular in robust statistics (Huber and Ronchetti 2009), while the model $f_{2}$ is a modification of the gross error model described in Hekimoglu and Erenoglu (2007). Figure 1 shows graphs of densities used in simulations on the positive half-line, because they are symmetric functions. Fig. 1 (right) is an enlarged image of tails of densities. Table 1 shows the probabilities of gross errors in the relevant range of values given in the top row of the table. The last column provides the standard deviations of distributions.

\section{Tested leveling networks}

We compared accuracy of estimators LS, IDS and HU in the four leveling networks analysed in our department. Parameters of the networks such as structure of design matrices, inverse weights and observations are shown in the Appendix 1. Below we present short summaries and diagrams.

Sieć 1 (Prószyński and Kwaśniak 2002, p. 96) is a small network in which observations have high, internal reliability indices. In particular, the network consists of 10 points and 21 observations. Internal reliability indices for individual observations are within the range of $0.66 \div 0.83$. We modified original weights of observations for consistency with the graph of Siec 1 shown in Figure 2a. 
Densities

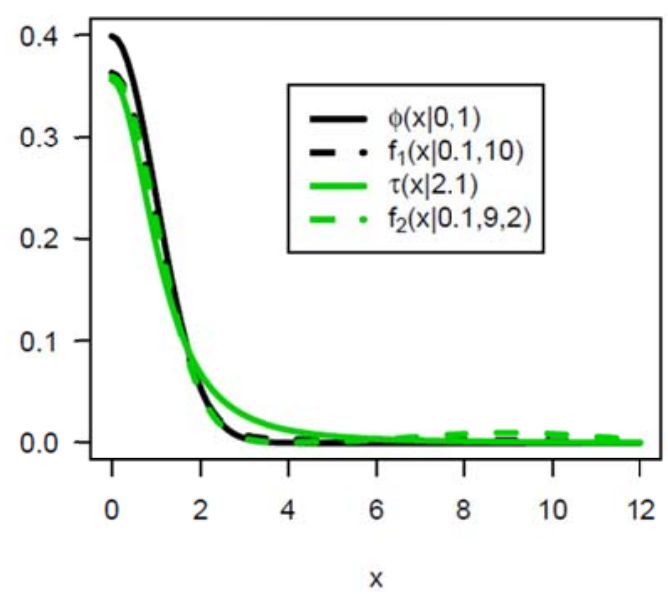

Densities

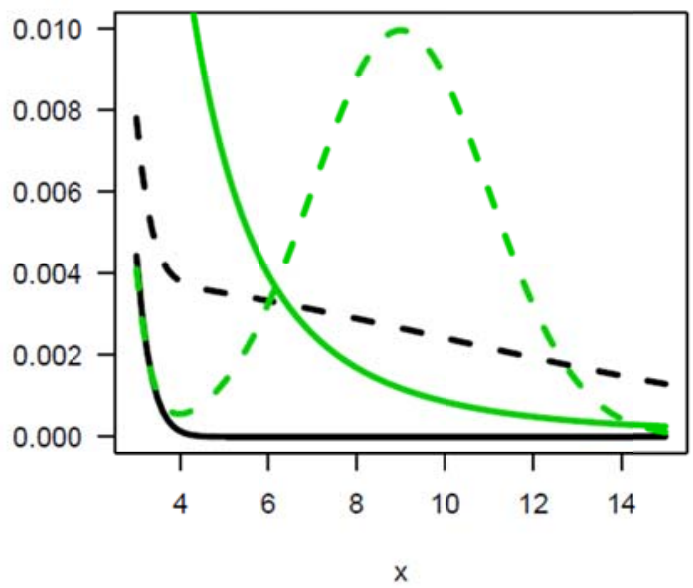

Fig. 1. Densities of the gross error distributions used in simulations.

Table 1. Probabilities of gross errors. In the column denoted „a-b“ we show $P\{a \leq|X| \leq b\}$.

\begin{tabular}{|c|c|c|c|c|c|c|c|}
\hline$f-a-b$ & $0-3$ & $3-6$ & $6-9$ & $9-12$ & $12-15$ & $15-18$ & $\sigma_{f}$ \\
\hline$\phi(x \mid 0,1)$ & 0.99730 & 0.00270 & 0.00000 & 0.00000 & 0.00000 & 0.00000 & 1.00 \\
\hline$\tau(x \mid 2.1)$ & 0.91001 & 0.06626 & 0.01335 & 0.00466 & 0.00213 & 0.00114 & 4.58 \\
\hline$f_{1}(x \mid 0.1,10)$ & 0.92115 & 0.02400 & 0.01804 & 0.01380 & 0.00965 & 0.00618 & 3.30 \\
\hline$f_{2}(x \mid 0.1,9,2)$ & 0.89770 & 0.00898 & 0.04332 & 0.04332 & 0.00655 & 0.00014 & 3.07 \\
\hline
\end{tabular}

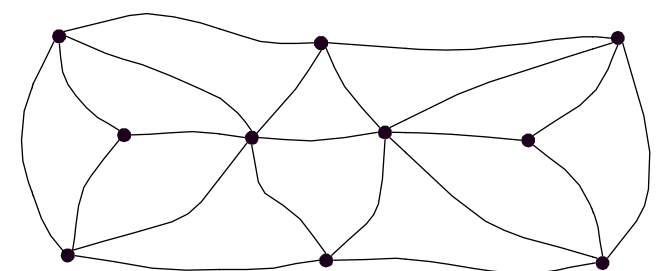

(a)

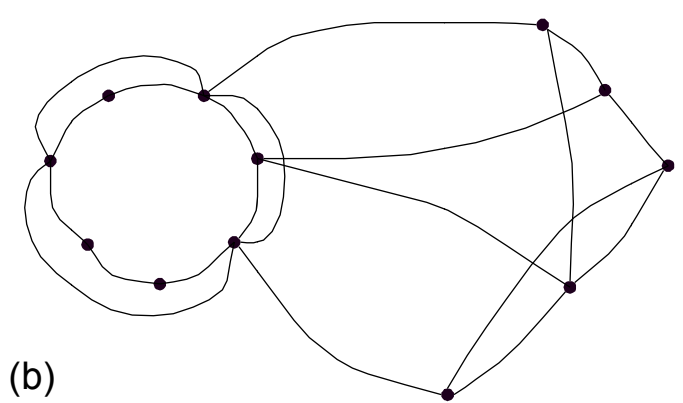

(b)

Fig. 2. Schemes of control leveling networs: (a) Sieć 1, (b) Sieć 2

Sieć 2 (Prószyński and Kwaśniak 2006, p. 92) consists of 12 points and 20 observations. The mean value of internal reliability index is equal to 0.67 (Fig. 2b).

The remaining two networks: Network Łazienki (Malarski et al. 2012) and Network Św. Anna (Malarski et al. 2010) are the result of real jobs in our department. These moderately large networks have more dispersed internal reliability indices than small networks. In the Łazienki network there are 53 points connected by 65 observations; in the St. Anna network 66 points and 80 observations, respectively. Diagrams of these networks are shown in Figure 3 and Figure 4. 


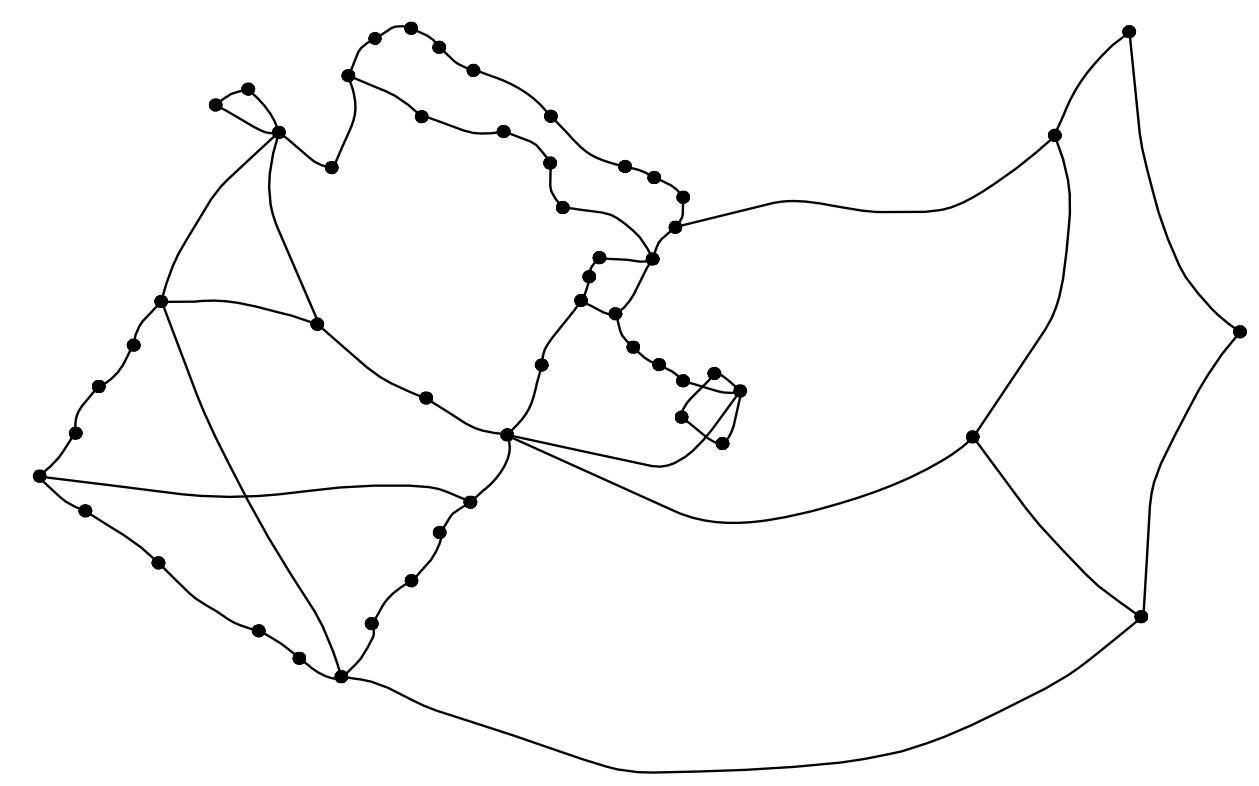

Fig. 3. Network Łazienki

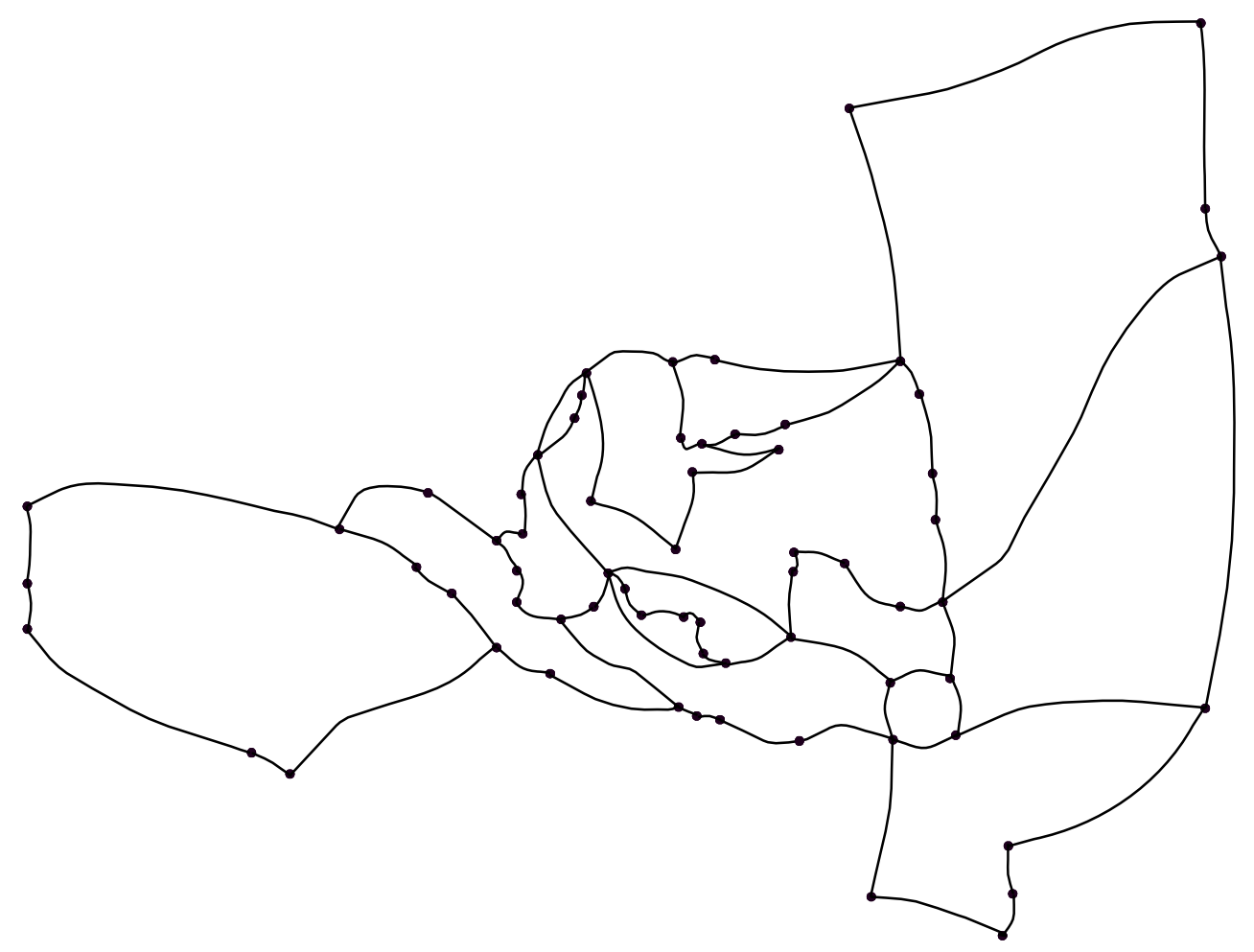

Fig. 4. Network Św. Anna

Table 2 contains parameters of the tested network: the number of observations $n$, the number of benchmarks $p$, the mean error of the typical measurement (given in $\mathrm{mm}$ ) and quartiles of internal network reliability indices. 
Table 2. Parameters of tested networks

\begin{tabular}{|c|c|c|c|c|c|c|c|c|}
\hline \multirow{2}{*}{ Network } & \multirow{2}{*}{$\mathrm{n}$} & \multirow{2}{*}{$\mathrm{p}$} & \multirow{2}{*}{$\sigma_{0}$} & \multicolumn{5}{|c|}{ Quartiles of internal reliability indices } \\
\cline { 6 - 10 } & & & & $\mathrm{min}$ & $\mathrm{Q}_{1}$ & med. & $\mathrm{Q}_{3}$ & $\max$ \\
\hline Sieć 1 & 21 & 10 & 0.08 & 0.66 & 0.72 & 0.75 & 0.81 & 0.83 \\
\hline Sieć 2 & 20 & 12 & 0.08 & 0.39 & 0.55 & 0.67 & 0.79 & 0.83 \\
\hline Łazienki & 65 & 53 & 0.05 & 0.26 & 0.38 & 0.41 & 0.50 & 0.71 \\
\hline Św. Anna & 80 & 66 & 0.05 & 0.22 & 0.35 & 0.38 & 0.49 & 0.79 \\
\hline
\end{tabular}

\section{Monte Carlo simulation}

For each network $\mathbf{A}$, using original observations $\mathbf{y}$ and inverse weights given in the Appendix, we computed a solution $\mathbf{x}$ by LS and considered it in simulations as true. Indeed, these LS estimators were found to be correct by surveyors and customers, thus we can accept pairs $(\mathbf{A}, \mathbf{x})$ as realistic models. We also used original a priori average error of observation $\sigma_{0}$.

For given network $\left(\mathbf{A}, \mathbf{x}, \sigma_{0}\right)$ and given measurement error density $f$ the following Monte Carlo simulation was repeated.

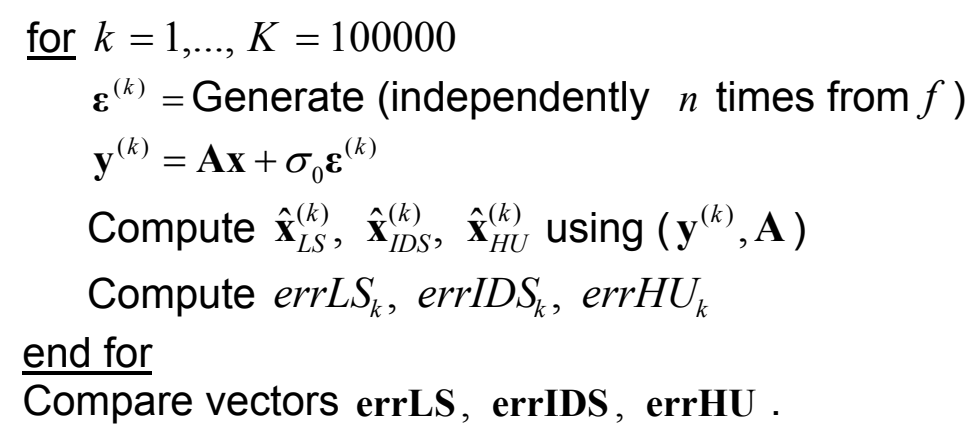

\section{Comparison of estimators}

Figures 5 and 6 present boxplots for data collected in errLS, errIDS, errHU. Plots on the top of the figures correspond to the gross error density $f_{1}(x \mid 0.1,10)$, plots in the middle of figures are connected to $\tau(x \mid 2.1)$, and on the bottom of the figures we can see results of simulations for $f_{2}(x \mid 0.1,9,2)$. The scale on the vertical axis corresponds to the values of the estimation errors given in $\mathrm{mm}$. On the plot, the $\mathrm{y}$ coordinate of the lower line of the box is equal to the first quartile $Q_{1}$, but $\mathrm{y}$ coordinate of the upper line of the box corresponds to third quartile $Q_{3}$. Thus the length of the box is equal to the interquartile range. Lines in the middle of the boxes denote medians. Sections shown by the dotted line, the so-called whiskers, show the spread of common values. It cannot be longer than one and a half of the interquartile range. Outliers are omitted on the plots. 
$0.9 \phi(x \mid 0,1)+0.1 \phi(x \mid 0,10)$

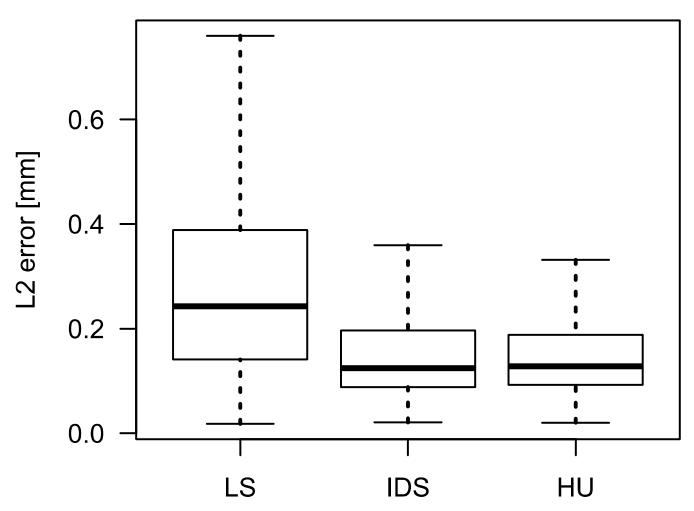

Siec 1

$\tau(\mathbf{x} \mid 2.1)$

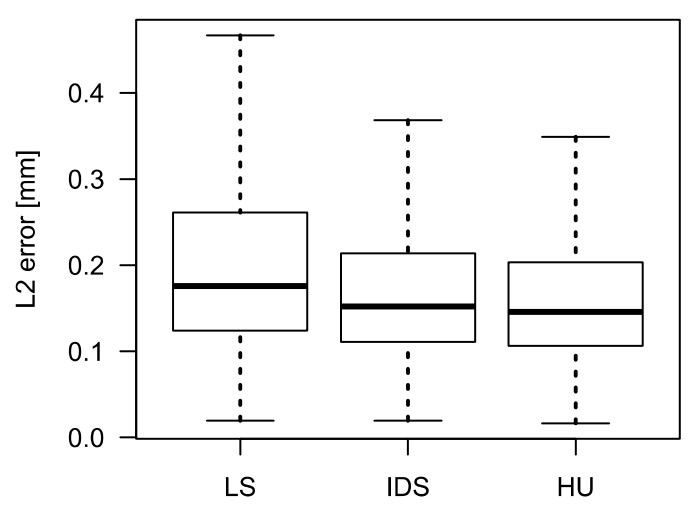

Siec 1

$0.9 \phi(x \mid 0,1)+0.05 \phi(x \mid-9,2)+0.05 \phi(x \mid 9,2)$

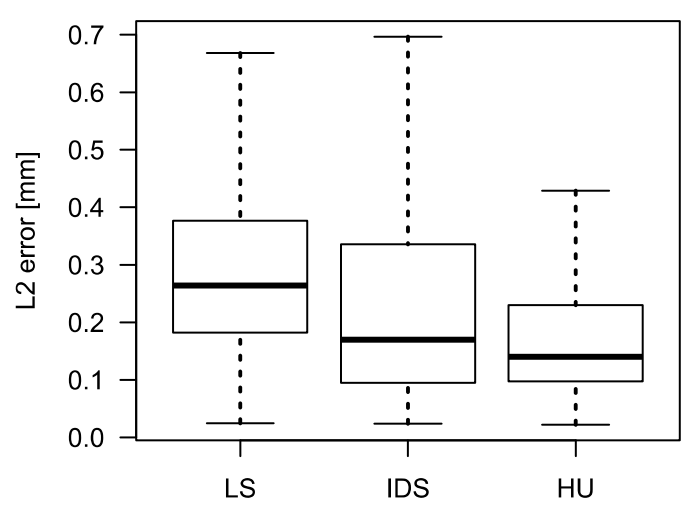

Siec 1
$0.9 \phi(x \mid 0,1)+0.1 \phi(x \mid 0,10)$

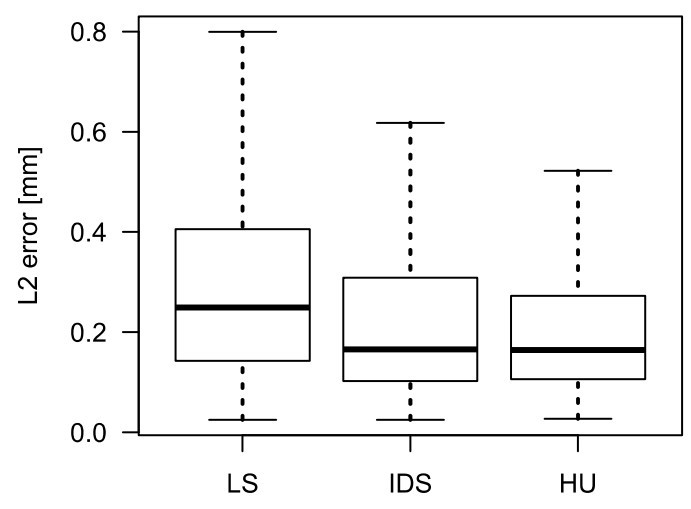

Siec 2

$\tau(x \mid 2.1)$

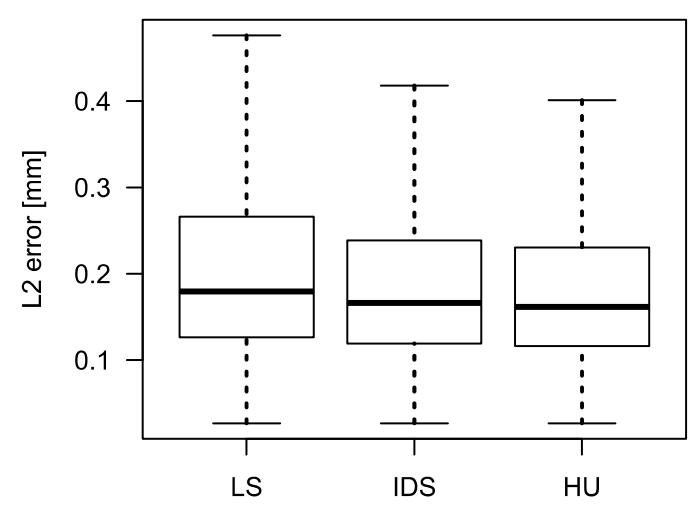

Siec 2

$0.9 \phi(x \mid 0,1)+0.05 \phi(x \mid-9,2)+0.05 \phi(x \mid 9,2)$

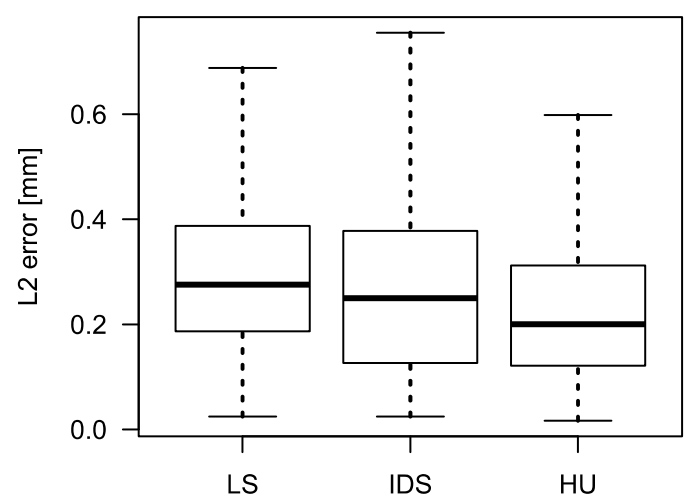

Siec 2

Fig. 5. Boxplots for estimation errors in small networks 
$0.9 \phi(x \mid 0,1)+0.1 \phi(x \mid 0,10)$

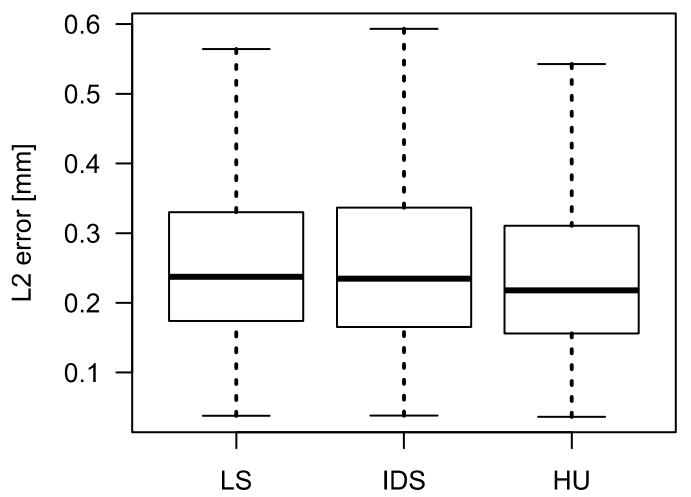

Lazienki

$\tau(\mathbf{x} \mid 2.1)$

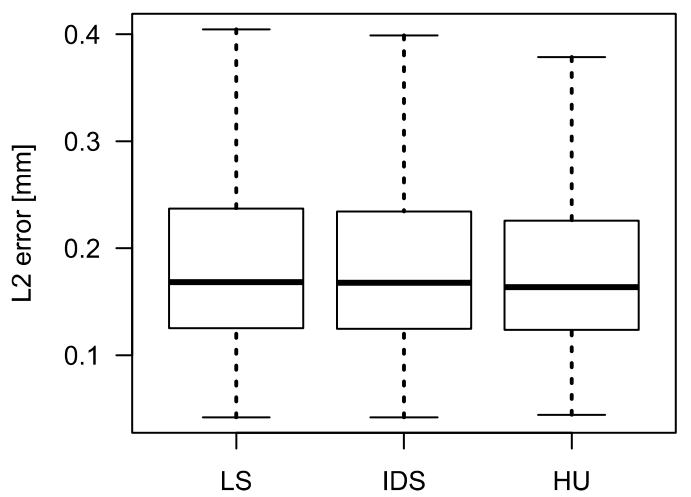

Lazienki

$0.9 \phi(x \mid 0,1)+0.05 \phi(x \mid-9,2)+0.05 \phi(x \mid 9,2)$

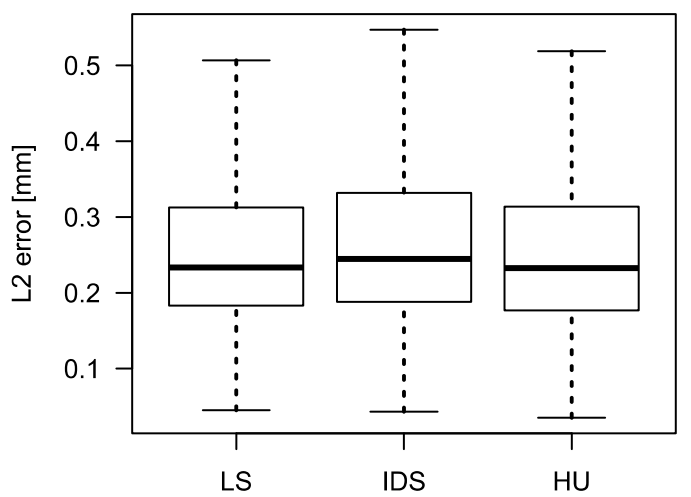

Lazienki
$0.9 \phi(x \mid 0,1)+0.1 \phi(x \mid 0,10)$

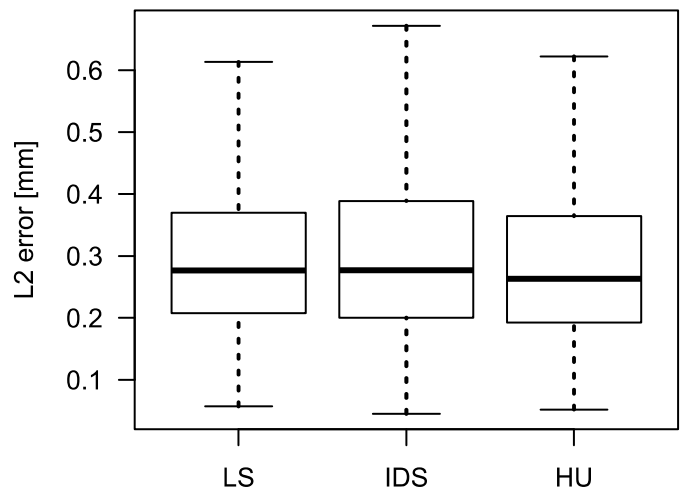

Sw.Anna

$\tau(\mathbf{x} \mid 2.1)$

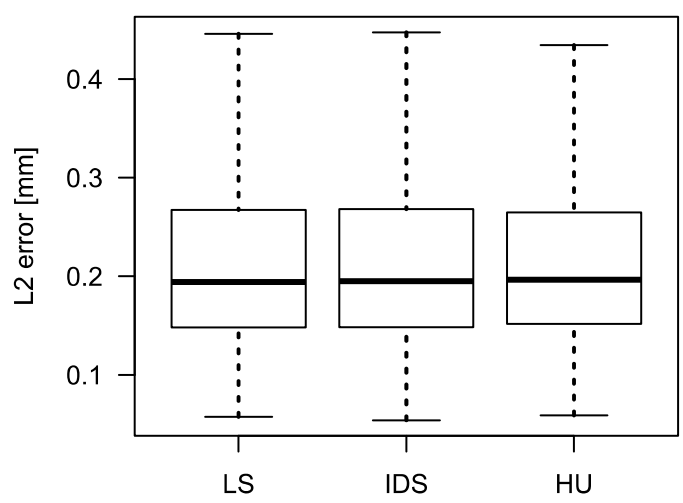

Sw.Anna

$0.9 \phi(x \mid 0,1)+0.05 \phi(x \mid-9,2)+0.05 \phi(x \mid 9,2)$

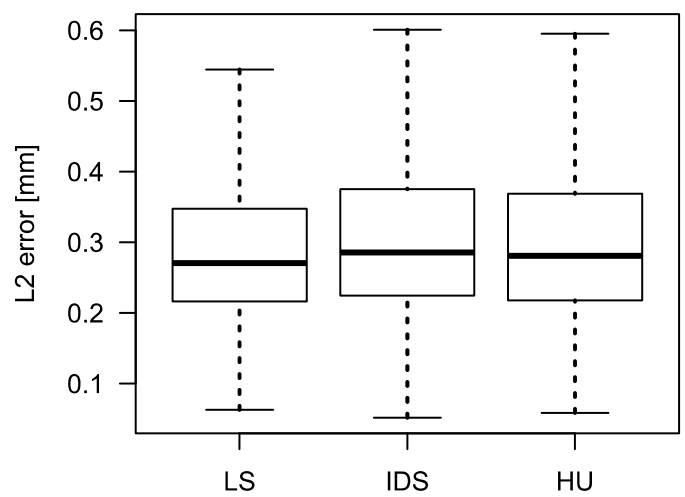

Sw.Anna

Fig. 6. Boxplots for estimation errors in networks Łazienki and Św. Anna 
Let us observe that the distribution $\tau$ despite the largest $\sigma$ (see. Table. 1) at least differentiates error of estimators. For small networks the mean value of the estimation error is less while using the estimators IDS or HU than LS. This is not observed in the case of large networks. For small networks and the gross error distributions $f_{1}$ or $\tau$, the estimaton error of the robust methods is less dispersed around the mean then the error of LS. For distribution $f_{2}$ better results are obtained using HU than IDS. For large networks, there are no significant differences between the error of LS and the error of the robust methods.

\section{Conclusions}

- Small networks are strong - their median internal reliability indices are about 0.7. Large networks are weaker with median internal reliability indices about 0.4 .

- For small networks the estimaton error of the robust methods is less than the error of LS, which confirms results in the literature. Moreover the Huber method has a smaller interquartile range than the iterative data snooping method.

- For large networks, there are no significant differences between the errors of LS, IDS and HU despite the fact that in considered error distributions outliers" probabilities are many times greater than for the normal distribution.

- Although the large networks are not strong, the average estimation error is comparable to the average error of the typical observations, so is acceptably small.

\section{Acknowledgments}

The author is greatly indebted to Piotr Pokarowski for his helpful suggestions which made this work possible.

\section{References}

Hekimoglu, S., \& Erenoglu, R. C. (2007). Effect of heteroscedasticity and heterogeneousness on outlier detection for geodetic networks. Journal of Geodesy, 81(2), 137-148. doi:10.1007/s00190-006-0095-z

Huber, P. J., \& Ronchetti, E. M. (2009). Robust Statistics. John Wiley \& Sons, New York

Knight, N. L., \& Wang, J. (2009). A comparison of outlier detection procedures and robust estimation methods in GPS positioning. Journal of Navigation, 62, 699709. doi: 10.1017/S0373463309990142

Koch, K. R., \& Kargoll, B. (2013). Expectation maximization algorithm for the variance-inflation model by applying the t-distribution. Journal of Applied Geodesy, 7(3), 217-225. doi:10.1515/jag-2013-0007

Kwaśniak, M. (2011). Effectiveness of chosen robust estimation methods compared to the level of network reliability. Geodesy and Cartography, 60(1), 3-19. doi:10.2478/v10277-012-0014-9

Malarski, R., et al. (2010). Wyznaczenie przemieszczeń poziomych i pionowych Kościoła Akademickiego Św. Anny w Warszawie. Monografia, Zakład Geodezji Inżynieryjnej i Pomiarów Szczegółowych, Wydział Geodezji i Kartografii Politechniki Warszawskiej, Warszawa

Malarski, R., et al. (2012). Wyznaczenie przemieszczeń pionowych Pałacu na Wyspie wraz z tarasem północnym i południowym oraz odchyleń od pionu murów 
oporowych tarasu północnego. Monografia, Zakład Geodezji Inżynieryjnej i Pomiarów Szczegółowych, Wydział Geodezji i Kartografii Politechniki Warszawskiej, Warszawa

Prószyński, W., \& Kwaśniak, M. (2002). Niezawodność sieci geodezyjnych. Oficyna Wydawnicza Politechniki Warszawskiej, Warszawa

Prószyński, W., \& Kwaśniak, M. (2006). Podstawy geodezyjnego wyznaczania przemieszczeń. Oficyna Wydawnicza Politechniki Warszawskiej, Warszawa

R Core Team (2013). R: A language and environment for statistical computing. $R$ Foundation for Statistical Computing, Vienna, Austria. URL http://www.Rproject.org/.

\section{Authors:}

Maria Pokarowska ${ }^{1)}$, mpokarowska@gik.pw.edu.pl

1) Chair of Engineering Geodesy and Control-Measuring Systems,

Faculty of Geodesy and Cartography,

Warsaw University of Technology,

PI. Politechniki 1, 00-661 Warsaw, Poland 


\section{Appendix 1: Parameters of the test networks}

siec 1, sigma $0=0.08$

\begin{tabular}{|c|c|c|c|c|}
\hline & from & to & $y$ & $\begin{array}{c}\text { inverse } \\
\text { weight }\end{array}$ \\
\hline 1 & 1 & 2 & -485.27 & 2.0 \\
\hline 2 & 1 & 7 & 1035.00 & 2.8 \\
\hline 3 & 1 & 8 & 640.03 & 2.8 \\
\hline 4 & 2 & 3 & 344.91 & 2.5 \\
\hline 5 & 2 & 6 & 205.11 & 2.5 \\
\hline 6 & 2 & 7 & 1519.91 & 4.0 \\
\hline 7 & 2 & 8 & 1124.82 & 3.7 \\
\hline 8 & 2 & 9 & -629.92 & 2.5 \\
\hline 9 & 3 & 4 & 565.07 & 1.8 \\
\hline 10 & 3 & 5 & 919.79 & 3.7 \\
\hline 11 & 3 & 6 & -139.98 & 2.6 \\
\hline 12 & 3 & 9 & -975.12 & 2.8 \\
\hline 13 & 3 & 10 & 1209.66 & 3.4 \\
\hline 14 & 4 & 5 & 355.17 & 2.3 \\
\hline 15 & 4 & 10 & 644.96 & 2.5 \\
\hline 16 & 5 & 6 & -1060.38 & 3.7 \\
\hline 17 & 5 & 10 & 290.19 & 4.8 \\
\hline 18 & 6 & 7 & 1315.31 & 4.4 \\
\hline 19 & 7 & 8 & -395.20 & 4.7 \\
\hline 20 & 8 & 9 & -1755.09 & 4.0 \\
\hline 21 & 9 & 10 & 2185.07 & 3.7 \\
\hline
\end{tabular}

Sw. Anna, sigma0 $=0.05$

\begin{tabular}{|c|c|c|c|c|}
\hline & from & to & $y$ & $\begin{array}{c}\text { inverse } \\
\text { weight }\end{array}$ \\
\hline 1 & 104 & 102 & 0.50 & 2.0 \\
\hline 2 & 102 & 103 & -0.45 & 1.0 \\
\hline 3 & 103 & 100 & -0.06 & 3.0 \\
\hline 4 & 100 & 3 & 0.00 & 3.0 \\
\hline 5 & 3 & 2 & 0.11 & 2.0 \\
\hline 6 & 2 & 106 & 0.07 & 1.0 \\
\hline 7 & 2 & 1 & 0.05 & 1.0 \\
\hline 8 & 1 & 6 & -0.17 & 1.0 \\
\hline 9 & 6 & 7 & 0.14 & 1.0 \\
\hline 10 & 7 & 8 & -0.10 & 1.0 \\
\hline 11 & 8 & 9 & 0.08 & 1.0 \\
\hline 12 & 9 & 10 & 0.14 & 1.0 \\
\hline 13 & 10 & 113 & -0.11 & 1.0 \\
\hline 14 & 113 & 109 & -0.07 & 1.0 \\
\hline 15 & 109 & 108 & 0.07 & 1.0 \\
\hline 16 & 108 & 107 & -0.17 & 1.0 \\
\hline 17 & 107 & 6 & 0.02 & 1.0 \\
\hline 18 & 107 & 106 & 0.21 & 2.0 \\
\hline 19 & 106 & 104 & -0.17 & 3.0 \\
\hline 20 & 10 & 11 & -0.05 & 2.0 \\
\hline 21 & 11 & 33 & -0.05 & 1.0 \\
\hline 22 & 10 & 37 & 0.02 & 1.5 \\
\hline 23 & 37 & 36 & -0.01 & 1.0 \\
\hline 24 & 36 & 35 & 0.08 & 1.0 \\
\hline 25 & 35 & 34 & -0.03 & 1.0 \\
\hline 26 & 34 & 33 & -0.09 & 1.0 \\
\hline 27 & 33 & 30 & -0.95 & 2.0 \\
\hline 28 & 30 & 52 & 0.52 & 3.0 \\
\hline
\end{tabular}

siec 2, sigma0 $=0.08$

\begin{tabular}{|c|c|c|c|c|}
\hline & from & to & $\mathrm{y}$ & $\begin{array}{c}\text { inverse } \\
\text { weight }\end{array}$ \\
\hline 1 & 1 & 2 & 1.9 & 1 \\
\hline 2 & 2 & 3 & 0.3 & 2 \\
\hline 3 & 3 & 4 & -0.7 & 1 \\
\hline 4 & 4 & 5 & -0.3 & 2 \\
\hline 5 & 5 & 6 & -2.1 & 2 \\
\hline 6 & 6 & 7 & -0.9 & 2 \\
\hline 7 & 7 & 1 & 1.2 & 2 \\
\hline 8 & 2 & 5 & -0.1 & 4 \\
\hline 9 & 5 & 7 & -2.5 & 3 \\
\hline 10 & 7 & 2 & 2.9 & 3 \\
\hline 11 & 101 & 2 & -1.0 & 2 \\
\hline 12 & 1 & 102 & 3.8 & 5 \\
\hline 13 & 102 & 103 & -0.1 & 2 \\
\hline 14 & 103 & 104 & 0.3 & 1 \\
\hline 15 & 104 & 105 & -0.3 & 1 \\
\hline 16 & 105 & 102 & 0.1 & 4 \\
\hline 17 & 102 & 101 & -0.5 & 3 \\
\hline 18 & 101 & 103 & 0.2 & 4 \\
\hline 19 & 104 & 1 & -4.4 & 4 \\
\hline 20 & 7 & 105 & 4.8 & 3 \\
\hline
\end{tabular}

Lazienki, sigma0 $=0.05$

\begin{tabular}{|c|c|c|c|c|}
\hline & from & to & $y$ & $\begin{array}{l}\text { inverse } \\
\text { weight }\end{array}$ \\
\hline 1 & 14 & 100 & 0.42 & 2 \\
\hline 2 & 100 & 101 & -0.26 & 2 \\
\hline 3 & 101 & 102 & -0.24 & 1 \\
\hline 4 & 102 & 103 & -0.12 & 2 \\
\hline 5 & 103 & 104 & 0.01 & 3 \\
\hline 6 & 104 & 100 & 0.61 & 2 \\
\hline 7 & 104 & 50 & 0.93 & 4 \\
\hline 8 & 101 & 24 & 0.34 & 2 \\
\hline 9 & 14 & 13 & 0.08 & 1 \\
\hline 10 & 13 & 11 & -0.06 & 1 \\
\hline 11 & 11 & 12 & 0.05 & 1 \\
\hline 12 & 12 & 25 & -0.31 & 1 \\
\hline 13 & 25 & 26 & -1.29 & 1 \\
\hline 14 & 26 & 27 & 0.87 & 1 \\
\hline 15 & 27 & 28 & 0.47 & 1 \\
\hline 16 & 28 & 29 & -0.15 & 1 \\
\hline 17 & 29 & 30 & -0.01 & 1 \\
\hline 18 & 30 & 31 & -0.01 & 1 \\
\hline 19 & 31 & 28 & 0.17 & 1 \\
\hline 20 & 28 & 14 & 0.19 & 1 \\
\hline 21 & 12 & 8 & 0.17 & 1 \\
\hline 22 & 11 & 10 & 0.05 & 1 \\
\hline 23 & 10 & 9 & 0.10 & 1 \\
\hline 24 & 9 & 8 & 0.07 & 1 \\
\hline 25 & 8 & 24 & 0.26 & 1 \\
\hline 26 & 24 & 23 & 0.03 & 1 \\
\hline 27 & 23 & 22 & -0.20 & 1 \\
\hline 28 & 22 & 21 & 0.87 & 2 \\
\hline
\end{tabular}




\begin{tabular}{|c|c|c|c|c|}
\hline 29 & 52 & 51 & 0.01 & 1.0 \\
\hline 30 & 51 & 31 & 0.27 & 2.0 \\
\hline 31 & 31 & 32 & 0.03 & 1.0 \\
\hline 32 & 32 & 35 & 0.24 & 2.0 \\
\hline 33 & 1 & 4 & -0.11 & 2.0 \\
\hline 34 & 4 & 3 & -0.05 & 1.0 \\
\hline 35 & 4 & 15 & 1.49 & 3.0 \\
\hline 36 & 15 & 16 & -0.20 & 2.0 \\
\hline 37 & 41 & 23 & -0.96 & 1.0 \\
\hline 38 & 16 & 17 & -0.05 & 1.0 \\
\hline 39 & 17 & 18 & -0.67 & 1.0 \\
\hline 40 & 16 & 22 & -1.23 & 2.0 \\
\hline 41 & 22 & 21 & -0.22 & 1.0 \\
\hline 42 & 22 & 221 & -0.27 & 1.0 \\
\hline 43 & 221 & 23 & -0.09 & 1.0 \\
\hline 44 & 23 & 24 & -0.05 & 1.0 \\
\hline 45 & 24 & 25 & 0.27 & 1.0 \\
\hline 46 & 25 & 26 & 0.18 & 1.0 \\
\hline 47 & 26 & 200 & 0.85 & 2.0 \\
\hline 48 & 26 & 27 & -0.14 & 1.0 \\
\hline 49 & 27 & 28 & 0.24 & 1.0 \\
\hline 50 & 28 & 29 & -0.27 & 1.0 \\
\hline 51 & 29 & 54 & -0.82 & 1.0 \\
\hline 52 & 54 & 53 & 0.69 & 1.0 \\
\hline 53 & 53 & 30 & -0.65 & 1.0 \\
\hline 54 & 29 & 30 & -0.78 & 1.0 \\
\hline 55 & 22 & 29 & -0.13 & 5.0 \\
\hline 56 & 18 & 19 & -0.07 & 1.0 \\
\hline 57 & 19 & 20 & -0.65 & 1.0 \\
\hline 58 & 20 & 21 & -0.01 & 2.0 \\
\hline 59 & 22 & 15 & 1.43 & 4.0 \\
\hline 60 & 43 & 42 & -0.12 & 1.0 \\
\hline 61 & 42 & 41 & 0.79 & 1.0 \\
\hline 62 & 41 & 40 & 0.37 & 1.0 \\
\hline 63 & 40 & 39 & 0.34 & 1.0 \\
\hline 64 & 39 & 203 & -0.99 & 1.0 \\
\hline 65 & 203 & 3 & -0.43 & 2.0 \\
\hline 66 & 44 & 43 & 0.33 & 1.0 \\
\hline 67 & 44 & 45 & -0.23 & 1.0 \\
\hline 68 & 45 & 46 & 0.28 & 2.0 \\
\hline 69 & 43 & 56 & -0.47 & 5.5 \\
\hline 70 & 55 & 56 & 0.20 & 1.0 \\
\hline 71 & 55 & 112 & -0.26 & 5.0 \\
\hline 72 & 111 & 110 & 0.20 & 1.0 \\
\hline 73 & 110 & 46 & 0.13 & 4.0 \\
\hline 74 & 111 & 112 & -0.12 & 1.0 \\
\hline 75 & 46 & 200 & 1.24 & 5.0 \\
\hline 76 & 6 & 5 & -0.17 & 2.0 \\
\hline 77 & 5 & 12 & 0.52 & 3.0 \\
\hline 78 & 12 & 13 & -0.03 & 1.0 \\
\hline 79 & 13 & 14 & 0.12 & 1.0 \\
\hline 80 & 14 & 15 & 1.11 & 2.0 \\
\hline & & & & \\
\hline 53
\end{tabular}

\begin{tabular}{|c|c|c|c|c|}
\hline 29 & 21 & 20 & -0.37 & 1 \\
\hline 30 & 20 & 19 & 0.14 & 1 \\
\hline 31 & 19 & 18 & -0.37 & 2 \\
\hline 32 & 18 & 17 & 0.27 & 1 \\
\hline 33 & 17 & 16 & 0.01 & 1 \\
\hline 34 & 16 & 4 & -0.45 & 1 \\
\hline 35 & 8 & 71 & -0.14 & 1 \\
\hline 36 & 71 & 7 & 0.05 & 1 \\
\hline 37 & 7 & 6 & 0.09 & 2 \\
\hline 38 & 6 & 5 & -0.07 & 1 \\
\hline 39 & 5 & 4 & 0.26 & 1 \\
\hline 40 & 4 & 3 & -0.61 & 1 \\
\hline 41 & 3 & 2 & 0.14 & 1 \\
\hline 42 & 2 & 32 & -2.13 & 1 \\
\hline 43 & 2 & 34 & -0.68 & 1 \\
\hline 44 & 34 & 32 & -1.45 & 2 \\
\hline 45 & 2 & 1 & 0.15 & 2 \\
\hline 46 & 1 & 15 & -0.08 & 2 \\
\hline 47 & 15 & 14 & -0.03 & 1 \\
\hline 48 & 14 & 54 & 0.45 & 1 \\
\hline 49 & 54 & 53 & -0.55 & 1 \\
\hline 50 & 53 & 52 & 0.23 & 1 \\
\hline 51 & 52 & 51 & 0.09 & 1 \\
\hline 52 & 51 & 50 & 0.52 & 1 \\
\hline 53 & 50 & 49 & -0.30 & 1 \\
\hline 54 & 49 & 48 & -0.20 & 1 \\
\hline 55 & 48 & 47 & -0.26 & 1 \\
\hline 56 & 47 & 46 & 0.11 & 1 \\
\hline 57 & 46 & 45 & 0.18 & 1 \\
\hline 58 & 45 & 54 & 0.18 & 1 \\
\hline 59 & 45 & 44 & -0.23 & 1 \\
\hline 60 & 44 & 43 & 0.34 & 1 \\
\hline 61 & 43 & 42 & -0.77 & 1 \\
\hline 62 & 42 & 41 & -0.06 & 1 \\
\hline 63 & 41 & 2 & 0.41 & 2 \\
\hline 64 & 41 & 1 & 0.56 & 1 \\
\hline 65 & 41 & 50 & 1.19 & 1 \\
\hline
\end{tabular}

